\title{
Professor Samuel J. Danishefsky, extraordinary synthetic chemist and great mentor
}

\author{
Takeshi Kitahara ${ }^{1}$
}

Received: 4 March 2019 / Accepted: 6 March 2019 / Published online: 27 May 2019

(c) The Author(s), under exclusive licence to the Japan Antibiotics Research Association 2019

Professor Samuel J. Danishefsky was born in March 10, 1936 and raised in New Jersey. He got his B.S. at Yeshiva University in 1956. Taking interest in synthetic organic chemsitry, he did his graduate studies at Harvard University and received Ph.D. in 1962 under the guidance of Professor Peter Yates. Then, he performed postdoctoral work at Columbia University; the supervisor was Professor Gilbert Stork.

In 1963, he started his academic career at the University of Pittsburgh, where he became professor in 1971 and University Professor in 1978. In 1980, he moved to Yale University and was named Eugene Higgins Professor in 1983 and then Sterling Professor in 1989. In 1991, he also became Kettering Chair and Director of the laboratory of bioorganic chemistry, Sloan Kettering Institute, Memorial Sloan Kettering Cancer Center. He moved from Yale to Columbia University as professor of chemistry in 1993. He retired from both positions to become professor emeritus recently.

His achievements in organic synthesis have been very wide and deep from the invention of novel and useful synthetic reactions to the synthesis of so many complex organic compounds including natural products, carbohydrate-based antitumor vaccines and so on, many of which are related to pharmaceuticals.

Through his career as a synthetic chemist, he has not only been an extraordinary research scientist, but also a great mentor of chemical research. He has educated and supervised more than 300 graduate students and postdoctoral fellows over a half century, many of whom became university professors and top research leaders at companies

Takeshi Kitahara

t.kitahara@mbg.nifty.com

1 Professor Emeritus, The University of Tokyo, Guest Professor, Kitasato Institute for Life Sciences, Kitasato University, Tokyo, Japan and institutes internationally. Among them, about 30 Japanese people are included and as an example, described below is my own case.

In May, 1974, I joined his group at the University of Pittsburgh as a postdoctoral fellow and had stayed until May, 1976. The current target molecule was vernolepin, an antitumor sesquiterpene isolated from plant kingdom, but the method of constructing the skeleton had not been explored yet. Under his supervision, I could prepare the novel electron-rich silyloxy diene, later so-called the Danishefsky(-Kitahara) diene, which was extremely reactive even with poor dienophiles (cylohexenecarboxylates thought to be inert to the Diels-Alder reaction at that moment) to give the adducts smoothly. It was really Magic Moment and hyper-reactivity of this diene enabled us to afford the skeleton of vernolepin, and its total synthesis was accomplished in the shortest steps. Syntheses of many natural products were successively followed by Danishefsky's group. Later, it was found that Lewis acid catalyzed hetero Diels-Alder reaction of carbonyl compounds with this diene gave oxygene heterocycles efficiently. The latter discovery led Danishefsky into carbohydrate chemistry in which he has made his most important contributions to synthetic chemistry. Since then, more than 400 papers using this diene have been published worldwide.

Because of such outstanding research establishments as described above, he received so many awards and honors, some of which are shown as follows. In 1996, he received the Wolf Prize in Chemistry from the Israeli Academy of Sciences, sharing with Professor Gilbert Stork. In the same year, he received the Tetrahedron Prize for Creative Work in Organic Chemistry. He also received the Claude S. Hudson Award in Carbohydrate Chemistry (1997), Ehrlich Award from the French Pharmaceutical Society (1998), the Arthur C. Cope Award (1998), Nagoya Medal (Gold), Japan (1999), Benjamin Franklin Medal in Chemistry (2006), and the Roger Adams Award (2007). He has been a member of the National Academy of Sciences since 1986. 
I believe that most of Sam's former students and postdocs would be delighted to know the special issue of The Journal of Antibiotics dedicated to Professor Samuel J. Danishefsky being published. I am truly grateful to Professor Kuniaki Tatsuta, Editor-in-Chief, and Dr. Keiichi Ajito, SectionEditor, for their efforts and suggestions to publish this special issue. I also thank Professor Dirk Trauner and Professor Masayuki Inoue for organizing this special issue.

Finally, I sincerely hope that Professor Danishefsky may stay healthy, and continue his work in both basic research studies and to create clinically useful substances especially related to antitumor activities. 